Research, Society and Development, v. 9, n. 6, e42963452, 2020

(CC BY 4.0) | ISSN 2525-3409 | DOI: http://dx.doi.org/10.33448/rsd-v9i6.3452

\title{
As Contribuições de Paulo Freire para o empoderamento feminino no campo
}

Paulo Freire's Contributions to Women's Empowerment in the countryside

Contribuciones de Paulo Freire al empoderamiento de las mujeres en el campo

Recebido: 02/04/2020 | Revisado: 03/04/2020 | Aceito: 06/04/2020 | Publicado: 12/04/2020

\section{Sandra Maria Campos Alves}

ORCID: https://orcid.org/0000-0002-9343-9324

Instituto Federal de Educação, Ciência e Tecnologia do Rio Grande do Norte, Brasil

E-mail: sandra.campos@ifrn.edu.br

Gisélia Batista de Oliveira

ORCID: https://orcid.org/0000-0003-0014-4074

Instituto Federal de Educação, Ciência e Tecnologia do Rio Grande do Norte, Brasil

E-mail: giselia.oliveira.87@gmail.com

\section{Resumo}

O empoderamento feminino é um tema atual que abordam as relações de gêneros. Este artigo tem como objetivo analisar as contribuições de Paulo Freire ao empoderamento feminino no campo para a construção de uma sociedade camponesa igualitária nas relações de gêneros. Para a explanação do tema o texto está dividido em três tópicos: A Pedagogia Progressista e as Relações de Gênero; O Empoderamento Feminino Camponês em uma Perspectiva Freireana e As Relações de Trabalho entre os Gêneros no campo. A metodologia usada é a pesquisa bibliográfica. O empoderamento, segundo Paulo Freire, não é suficiente para uma transformação social, porém ele é um movimento importante, sendo assim, como um processo de transformação social. As mulheres empoderadas são sujeitos sociais e emancipadas. Capazes de perceberem, refletirem e interpretarem sua realidade social no sentido de individual e/ou coletivamente, produzirem mudanças significativas para a construção de uma sociedade mais humana e democrática.

Palavras-chave: Trabalho; Educação; Empoderamento.

\begin{abstract}
Women's empowerment is a current topic that addresses gender relations. This article aims to analyze Paulo Freire's contributions to female empowerment in the countryside to build an egalitarian peasant society in gender relations. For the explanation of the theme, the text is
\end{abstract}


divided into three topics: Progressive Pedagogy and Gender Relations; Peasant Female Empowerment in a Freirean Perspective and Labor Relations between Genders in the field. The methodology used is bibliographic research. Empowerment, according to Paulo Freire, is not enough for social transformation, but it is an important movement, and thus, as a process of social transformation. Empowered women are social and emancipated subjects. Able to perceive, reflect and interpret their social reality in the sense of individually and / or collectively, produce significant changes for the construction of a more humane and democratic society.

Keywords: Job; Education; Empowerment.

\section{Resumen}

El empoderamiento de las mujeres es un tema actual que aborda las relaciones de género. Este artículo tiene como objetivo analizar las contribuciones de Paulo Freire al empoderamiento femenino en el campo para construir una sociedad campesina igualitaria en las relaciones de género. Para la explicación del tema, el texto se divide en tres temas: pedagogía progresiva y relaciones de género; El empoderamiento de las mujeres campesinas en una perspectiva freireana y las relaciones laborales entre los géneros en el campo. La metodología utilizada es la investigación bibliográfica. El empoderamiento, según Paulo Freire, no es suficiente para la transformación social, pero es un movimiento importante y, por lo tanto, como un proceso de transformación social. Las mujeres empoderadas son sujetos sociales y emancipados. Capaz de percibir, reflexionar e interpretar su realidad social en el sentido individual y / o colectivo, produce cambios significativos para la construcción de una sociedad más humana y democrática.

Palabras clave: Trabajo; Educación; Empoderamiento.

\section{Introdução}

As tendências pedagógicas que estruturam o processo educativo brasileiro são baseadas em movimentos históricos, sociais e culturais. Para esse estudo, enfatiza - se as tendências progressistas que são libertadora representada por Paulo Freire, Libertária de Maurício Tragtenberg e Crítica - social de Demerval Saviani. O termo "progressista", emprestado de Snyders, é usado aqui para designar as tendências que, partindo de uma análise crítica das realidades sociais, sustentam implicitamente as finalidades sociopolíticas da educação. (Libâneo, 2006, p.21). 
Para Nóvoa (1998), Freire é o mais importante pedagogo de língua portuguesa do século XX. A sua vida e a sua obra impõem-no como uma referência obrigatória, uma vez que transporta memórias e conceitos essenciais para o esforço científico de pensar a educação e a escola. Para Paulo Freire, a formação permanente pressupõe que o formador e o formando se compreendam como seres inconclusos e que essa é uma condição humana que impele o homem a se enveredar, curiosamente, na busca pelo conhecimento de si e do mundo. Freire considera que essa é uma vocação ontológica e que, ao perceberem que o destino não está dado, os sujeitos possam, cada vez mais, ser capazes de (re)escrever suas histórias, contribuindo para a mudança da ordem social injusta que desumaniza e oprime (Saul \& Saul, 2016)

Paulo Freire e Ira Shor em Medo e Ousadia: O cotidiano do professor (1986), livro estruturado em forma de diálogo para falar de uma pedagogia dialógica e utilizam o termo empowerment [empoderamento] no contexto da educação. Os educandos ao se perceberem como sujeitos que entendem e refletem de forma crítica sobre sua realidade de opressão e desvantagem social, econômica e política; anseiam em modificar radicalmente essa opressão. No decorrer desse processo, eles são capazes de notar o poder existente em seu grupo e nas reações externas e assim alcançam os princípios do empoderamento como as lutas de classe social. (Freire \& Shor,1986)

O empoderamento, segundo Paulo Freire, não é suficiente para uma transformação social, porém ele é um passo fundamental no processo de transformação social. Sendo assim, as mulheres empoderadas são sujeitos sociais e emancipadas capazes de perceberem, refletirem e interpretarem sua realidade social no sentido de, individual e/ou coletivamente, produzirem mudanças significas para a construção de uma sociedade mais humana e democrática.

A pesquisa usada nesse artigo será uma pesquisa bibliográfica, isso se dará através da verificação de documentos, como livros, artigos, teses etc.

Esse artigo tem como objetivo de analisar as contribuições de Paulo Freire ao empoderamento feminino no campo para a construção de uma sociedade camponesa igualitária nas relações de gênero e trabalho. 


\section{Metodologia}

Esse artigo trata de uma pesquisa bibliográfica de cunho qualitativo, pois demandou a leituras de vários textos científicos para sua elaboração, corroborando o conceito de pesquisa bibliográfica temos

A pesquisa bibliografia é desenvolvida com base em material já elaborado, constituído principalmente de livros e artigos científicos. Embora em quase todos os estudos seja exibido algum tipo de trabalho dessa natureza, há pesquisas desenvolvidas exclusivamente a partir de fontes bibliográficas. Boa parte dos estudos exploratórios pode ser definida como pesquisas bibliográficas. (GIL, 2002, p.44.).

Para esse estudo foi necessária a leitura de livros, artigos e periódicos sobre a temática abordada.

\section{A Pedagogia Progressista Libertadora e as Relações de Gênero}

A Prática educacional é um fator da formação da formação humana considerada como prática social e cultural. As práticas educativas que orientam os professores no processo de ensino aprendizagem são as tendências pedagógicas. Luckesi (1990, p.53) conceitua tendência pedagógica como "as diversas teorias filosóficas que pretenderam dar conta da compreensão e da orientação da prática educacional em diversos momentos e circunstancias da história humana."

Para Libâneo as tendências pedagógicas classificam -se em dois grandes grupos: Liberal e progressista. O termo liberal se refere ao sistema capitalista que sustenta a ideia de que a escola tem por função preparar os indivíduos para o desempenho de papeis sociais, de acordo com as aptidões individuais. Entretanto, o vocábulo progressista emprestado de Snyders, é usado aqui para designar as tendências que, partindo de uma análise crítica das realidades sociais, sustentam implicitamente as finalidades sociopolíticas da educação (Libâneo, 2006, p.21).

A Pedagogia Liberal está dividida em: Tradicional; Renovada Progressivista; Renovada não diretiva e tecnicista. Elas são baseadas em princípios liberais, a educação e os conteúdos sobressaem no processo de ensino e aprendizagem, não considerando as experiências vividas dos alunos e como consequência o saber se torna instrumento de poder e dominação entre as classes sociais 
A Pedagogia progressista está classificada em: Libertadora; Libertária e Crítica Social do Conteúdo. A escola tem o papel transformador dos educandos em sujeitos críticos e transformadores da sociedade, corroborando com essa afirmação Saviani diz

1- Prática social - ponto de partida da prática educativa, é comum a professor e aluno. Entretanto, em relação a essa pratica comum, o professor assim como os alunos podem posicionar-se diferentemente enquanto agentes sociais diferenciados. E do ponto de vista pedagógico há uma diferença essencial que não pode ser perdida de vista: o professor, de um lado, e os alunos, de outro, encontram-se em níveis diferentes de compreensão (conhecimento e experiência) da pratica social... A compreensão do professor é sintética porque implica certa articulação dos conhecimentos e das experiências que detém relativamente à pratica social. (Saviani, 2009, p. 63)

Para Freire "o respeito à autonomia e a dignidade de cada um é um imperativo ético e não podemos conceder uns aos outros. (Freire, 2011, p.58)". A prática social é relevante no processo de ensino - aprendizagem na pedagogia progressista.

Diferentemente do tradicionalismo do passado e desenvolvendo um papel socialmente mais igualitário, com o passar do tempo a escola aprendeu a respeitar as diferenças. Celso Antunes (2006) reforça este pensamento quando diz que as diferenças existem, mas que cada um tem suas habilidades.

$\mathrm{O}$ respeito à subjetividade discutida nas obras de Freire e considerando o gênero feminino e suas lutas por direitos iguais a escola pode ser uma aliada ao combate da dominação masculina. Para isso, é necessário compreender o conceito de gênero segundo Butler "se constrói como fenômeno inconstante e contextual, o gênero não denota um ser substantivo, mas um ponto relativo de convergência entre conjuntos específicos de relações, cultural e historicamente convergentes. (Butler, 2003, p.29)" o conceito se dá pela as atribuições sociais e culturais dadas ao termo feminino e masculino.

As discussões sobre as relações de gênero são importantes em ambientes educacionais com finalidade de sensibilizar os educandos na transformação da sociedade corroborando com Freire (2011, p.59) que diz

Que alguém se torne machista, racista, classista, sei lá o quê, mas se assume como transgressor da natureza humana. Não me venha com justificativas genéticas, sociológicas ou históricas ou filosóficas para explicar a superioridade da branquitude sobre a negritude, dos homens sobre as mulheres, dos patrões sobre os empregados. Qualquer discriminação é imoral e lutar contra elas é um dever por mais que se reconheça a força dos condicionamentos a enfrentar. 
Para Gadotti (2001), a pedagogia é revolucionária, significa que ela não esconde as relações existentes entre educação e sociedade, entre educação e poder, ou seja, ela não esconde o papel ideológico, político, da educação.

Primeiro, a sociedade deve atentar para as diferenças autoritárias de determinados grupos sociais e a educação proporcionar práticas educativas que desenvolva nos sujeitos princípios éticos e respeito a sua subjetividade.

\section{O Empoderamento Feminino Camponês em uma Perspectiva Freireana}

A partir da segunda metade do século $\mathrm{XX}$ é que o termo é apropriado pelos movimentos sociais de luta contra o sistema de opressão, em favor da libertação da contracultura nos EUA, por exemplo. Desta forma, empowerment passa a ser entendido como sinônimo de emancipação social e se assenta no seio do discurso da luta por direitos civis, do movimento negro, das mulheres, dos homossexuais e das pessoas com deficiência (Baquero, 2012).

Schiffer (2013), afirma que até período de 1970, as políticas públicas assistencialista de desenvolvimento e reproduziam o perfil patriarcal nos lares, as mesmas dificultavam a igualdade de gênero, entretanto as mulheres se mobilizavam com o objetivo de transformar tais medidas.

O termo empoderamento no decorrer da história adquire vários significados, tornandose o termo polissêmico. Porém, para Sardenberg a atribuição ao termo duas vertentes principais e antagônicas entre si, primeiro tem o empoderamento das mulheres utilizado pelas instituições como a Organização das Nações Unidas (ONU)

é o empoderamento das mulheres visto como um instrumento para o desenvolvimento, para a democracia, para erradicar a pobreza, etc. Não é um fim em si próprio.” Alertar a sociedade para a necessidade da adoção de medidas tendentes a reduzir a discriminação de gênero, principalmente no plano econômico, para que, no futuro, homens e mulheres possam efetivamente desfrutar dos mesmos direitos, enquanto que o empoderamento defendido pelas feministas, consiste nos processos de libertação e, consequente, autodeterminação das mulheres. (Sardenberg, 2009, p.2,4)

Nessas perspectivas o termo empoderamento busca a equidade de gênero, mas na primeira refere - se apenas ao setor econômico e a segunda considera com significado amplo que inclui todos os setores e as mulheres conscientizadas lutam pela liberdade a opressão masculina na sociedade. 
O conceito de empoderamento feminino na perspectiva feminista é entendido de acordo com as discussões de Paulo Freire e também nos trabalhos de Gramsci. O termo empoderamento é caracterizado pela palavra poder, pois as feministas o conceituam como um processo de transformação das relações de poder entre os gêneros, isto é, um movimento das mulheres para conquistar autonomia e libertação da opressão patriarcal. Para Batliwala diz que

O termo empoderamento se refere a uma gama de atividades, da assertividade individual até à resistência, protesto e mobilização coletivas, que questionam as bases das relações de poder. No caso de indivíduos e grupos cujo acesso aos recursos e poder são determinados por classe, etnicidade e gênero. o empoderamento começa quando eles não apenas reconhecem as forças sistêmicas que os oprimem, como também atuam no sentido de mudar as relações de poder existentes. Portanto, o empoderamento é um processo dirigido para a transformação da natureza e direção das forças sistêmicas que marginalizam as mulheres e outros setores excluídos em determinados contextos. (Batliwala, 1994, p.130)

O empoderamento no panorama da Pedagogia de Freireana "o empoderamento individual é fundado numa percepção crítica sobre a realidade social, é fundamental, mas tal aprendizagem precisa ter relação coma transformação mais ampla da sociedade (Baquero, 2012, p.181), portanto essa forma de aprendizagem deve envolver outros setores da sociedade para ter essa transformação social.

As práticas educativas não são preceitos do território escolar, mas também as rotinas cotidianas do sujeito com a finalidade dos mesmos atuarem nas transformações necessárias para o seu desenvolvimento social.

\section{As Relações de Trabalho entre os Gêneros no campo}

O trabalho é uma característica essencialmente humana, através dele a humanidade consegue sua existência, a transformação do seu mundo e de suas futuras gerações, esse conceito de trabalho em consonância com o de Marx

Antes de tudo, o trabalho é um processo entre o homem e a natureza, um processo em que o homem, por sua própria ação, media, regula e controla seu metabolismo com a natureza. Ele mesmo se defronta com a matéria natural, como uma força natural. Ele põe em movimento as forças naturais pertencentes à sua corporalidade, braços e pernas, cabeça e mãos a fim de apropriar se da matéria natural numa forma útil para sua própria vida. Ao atual, por meio desse movimento sobre a natureza externa a ele e ao modificá-la, ele modifica ao mesmo tempo a sua própria natureza (Marx, 1986). 
Para Saviani (1994) pontua que no início da produção comunal não havia classes, homens, mulheres apenas indivíduos produzindo sua existência através do trabalho, nesse período não tinha divisão de trabalho entre os gêneros masculino e feminino. Em algum momento da história humana acontece à divisão de gênero que é construído a partir das relações sociais sobre as diferenças entre os sexos, fornecendo a codificação e o significado e a compreensão das complexas interações humanas. Essa questão não é biológica, porém é uma construção de identidades dos sujeitos.

No século XIX, inicia as lutas das mulheres e a conquista do direito ao voto, com o movimento denominado sufragista, na Inglaterra. No Brasil, na década 1910, o movimento feminista foi liderado pela bióloga Bertha Lurtz, lutava pelo direito ao voto, mas esse direito foi conquista em 1932 no país. Na década de 1980, as mulheres camponesas também estavam se organizando em movimentos sindicalistas rurais como o Movimento Autônomo de Mulheres Rurais - MMTR. (Deere, 2004).

Em Brasília, 1988, teve o Primeiro Seminário das Mulheres Trabalhadoras Rurais, nesse seminário as agricultoras conquistaram a inclusão na reforma agrária, direitos iguais para homens e mulheres rurais e urbanos em relação à legislação do trabalho aos benefícios de previdência social. Foi estipulado que esses benefícios referiam-se às trabalhadoras assalariadas temporárias e permanentes, bem como às agricultoras familiares, incluindo as trabalhadoras familiares não remuneradas.

A partir de 1990, houve um grande crescimento de mulheres nas lideranças dos movimentos sociais, especialmente no Movimento dos Sem Terra - MST. Entretanto, "mesmo havendo um aumento significativo da presença da mulher na luta pela terra, visando o acesso às terras de reforma agrária, apenas $12 \%$ dos lotes de terras em assentamentos no Brasil estão em nome das mulheres”. (Schewendler, 2009, p. 181)

O trabalho das mulheres na roça é considerado sem relevância para a família, Garcia Jr. (1993) aponta que a tarefa de plantar desempenhada pelas mulheres no roçado, é considerada trabalho se comparada com suas atividades domésticas, porém, se comparada com as atividades masculinas no roçado, plantar não é considerado trabalho.

Para Faria (2011), a divisão sexual do trabalho no campo é influenciada pela lógica capitalista do trabalho, tendo seus graus e funções no que tange o seu valor de troca no mercado. Concomitantemente as atividades ligadas à roça e a criação de animais são tomados como extensão do trabalho doméstico, uma espécie de "ajuda" e complemento executado pela figura feminina, o que dar consistência a hierarquia estabelecida na convivência na divisão do trabalho no campo. 
O trabalho doméstico permanece ainda muito resignado à mulher. As mulheres falam do desafio que é cuidar de filhos, idosos, animais pequenos entre outras atividades caseiras. No cotidiano da casa ainda é muito forte está "divisão natural e/ou biológica" do trabalho; permanecendo o trabalho caseiro, ou melhor, a função da mulher (como mãe, esposa ou filha) como um tipo de trabalho hierarquicamente "invisível", o trabalho doméstico (Hirata \& Kergat, 2007).

Neste sentido a qualificação do trabalho feminino é relacional, recebendo, muitas vezes, uma dupla avaliação. Estudos realizados sobre a divisão sexual do trabalho na agricultura apontam que as mulheres têm ocupado uma posição de subordinação à autoridade centralizada do marido, razão pela qual seu trabalho é, em muitos casos, definido como ajuda, mesmo quando elas trabalham tanto quanto os homens e realizam as mesmas atividades (Brumer, 2004).

$\mathrm{Na}$ divisão sexual das atividades, a responsabilidade pelo trabalho considerado produtivo (produção destinada à comercialização) é usualmente incumbência masculina, enquanto o trabalho reprodutivo (cuidado com as crianças, com a casa, preparação da comida), é considerado de responsabilidade das mulheres. Sendo menos reconhecido, o trabalho feminino permanece marcado por certa invisibilidade (Brumer \& Anjos, 2008). Isso acontece segundo Nobre (2005, p.44)

A valorização diferente do trabalho de mulheres e homens se explica pela existência de uma relação de hierarquia entre os gêneros. Essa relação tem sua base material na divisão sexual do trabalho, mas organiza, sem ordem de prioridades, aspectos econômicos, sociais, vivências particulares, símbolos e representações em imagens de constante movimento, como em um caleidoscópio.

As mulheres através de lutas de gêneros estão conquistando novas habilidades para com a finalidade de construir sua identidade através do trabalho com autonomia de sujeito ativo e transformador da sociedade com direitos e projetos de vida.

\section{Considerações Finais}

O artigo elaborado sobre a construção da subjetividade dos indivíduos e as relações de trabalho no campo entre os gêneros numa perspectiva de Paulo Freire. É relevante destacar que esse tema inquieta para algumas reflexões como os direitos femininos conquistados são 
(CC BY 4.0) | ISSN 2525-3409 | DOI: http://dx.doi.org/10.33448/rsd-v9i6.3452

muitos, porém é notório que as necessitam continuar na luta realmente ter uma sociedade que possui uma equidade de gêneros.

A Pedagogia Progressista libertadora pode contribuir para a transformação da sociedade através de práticas educativas transformadoras que envolva o conhecimento cientifico e o saber das convivências dos sujeitos, pois segundo Paulo Freire (2011, p.30) "a teoria sem a prática vira 'verbalismo', assim como a prática sem teoria, vira ativismo. No entanto, quando se une a prática com a teoria tem-se a práxis, a ação criadora e modificadora da realidade."

A literatura de Paulo Freire favorece a conquista da autonomia das mulheres, especialmente as agricultoras. O campo é um lugar de cultura patriarcal muito forte, por isso é importante às discussões sobre empoderamento feminino camponês. Uma ferramenta que pode construir uma sociedade camponesa com uma equidade de gêneros é a educação que pode ser a formal ou não informal, por que através dela as trabalhadoras camponesas podem conscientizar de seu poder nas relações do cotidiano e assim desenvolver o processo de empoderamento mais significativo na comunidade rural.

As trabalhadoras, atualmente, ocupam lugares públicos: sindicatos, associações, movimentos, conselhos, partidos políticos e têm neles um espaço assegurado. Neles, exigem o e conhecimento de sua voz pelos saberes e pela autonomia política que portam. Isso permite serem ouvidas e proporem demandas em relação aos seus direitos.

\section{Referências}

Antunes, C. (2006). Inteligências Múltiplas. Petrópolis - RJ, Vozes.

Baquero, R.V.Â. (2012). Empoderamento: instrumento de emancipação social? Uma discussão conceitual. Revista Debates, Porto Alegre, 6(1): 173-187, jan.-abr.

Batliwala, S. (1994.). The meaning of women's empowerment: new concepts from action. In: Sen, G.; Germain, A. \& Chen, L. C. (Ed.). Population policies reconsidered: health, empowerment and rights. Boston: Harvard University Press: 127-138.

Brumer, A.(2004). Gênero e agricultura: a situação da mulher na agricultura do Rio Grande do Sul. Rev. Estud. Fem. [online], Florianópolis,12(1). 
Disponível em 205-227.ISSN 0104-026X. https://doi.org/10.1590/S0104-

026X2004000100011. Acesso em 08/02/2020

A. \& Anjos, G. (2008). Relações de Gênero em Assentamentos: a noção de empoderamento em questão. In: Lopes, A. \& Butto, A. (2008). Mulheres na Reforma Agrária: A experiência recente no Brasil. Brasília: MDA.

Butler, J. (2003). Problemas de gênero. Feminismo e subversão da identidade. Rio de Janeiro: Civilização Brasileira.

Deere, C. D. (2004). Os direitos da mulher à terra e os movimentos sociais rurais na reforma agrária brasileira. Revista Estudos Feministas, Florianópolis: CFH/CCE/UFSC, 12(1).

Faria, N. (2011). Desafios para a Construção da Autonomia Econômica para as Mulheres.

In.: Autonomia econômica e empoderamento da mulher: textos acadêmicos. Brasília:

Fundação Alexandre de Gusmão.

Freire, P. (2011) Pedagogia da autonomia: saberes necessários à prática educativa. (43 ed.). São Paulo: Paz e Terra.

Freire, P. \& Shor, I. (1986) Medo e ousadia: o cotidiano do professor. Rio de Janeiro: Paz e Terra.

Gadotti, M. (1995). Escola Vivida, Escola Projetada, (2 ${ }^{\mathrm{a}}$ Ed), Campinas, SP: Papirus. Garcia, Júnior, A. R. (1993). Terra de trabalho. RJ: Paz e Terra.

Gil, A. C. (2002). Como elaborar projetos de pesquisa. (4ª ed.). São Paulo: Atlas.

Gonsalves, E.P. (2001). Iniciação à pesquisa científica. Campinas, SP: Alínea.

Hirata, H \& Kergoat, D. (2007). Novas configurações da divisão sexual do trabalho.

Cadernos de Pesquisa, 37 (132): 595-609, set./dez. 
Libâneo, J. C. (2002). Democratização da Escola Pública: a Pedagogia Crítico-Social dos Conteúdos. São Paulo, SP: Loyola.

Luckesi, C. C. (1994). Filosofia Da Educação. São Paulo: Cortez.

Marx, K. (1983). O Capital. São Paulo: Abril Cultural.

Nobre, M. Relações de Gênero e Agricultura Familiar. (2005) In: Nobre, M; Faria, N.

Siveira, M. L.(orgs). Feminismo e lutas das Mulheres: Análises e debates. São Paulo: SOF.

Nóvoa, A. (1998). Notas sobre um regresso adiado. Educação, sociedade e culturas. Porto, 10: $155-174$.

Disponível em: <http://www.fpce.up.pt/ciie/revistaesc/ESC10/10--dialogos.pdf>. Acesso em: 10 mar. 2020.

Saul, A. M. \& Saul, A. (2016). Contribuições de Paulo Freire para a formação de educadores: fundamentos e práticas de um paradigma contra-hegemônico. Educar em Revista. Curitiba, Brasil, 61: 19-35, jul./set.

Sardenberg, C. M. B. (, 2009). Liberal vs liberating empowerment: a Latin American feminist perspective. Pathways Working Paper 7, Pathways of Women's Empowerment, Brighton, UK: IDS - Institute of Development Studies.

Saviani, D. (1994). O trabalho como princípio educativo frente às novas tecnologias. In: Ferreti, Celso João et al. (Org.). Novas tecnologias, trabalho e educação: um debate multidisciplinar. Petrópolis: Vozes: 147-164.

Schefler, M. de L. N. (2013). Gênero, autonomia econômica e empoderamento. $O$ real $e \quad o$ aparente: sistematização de processos de investigação-ação elou de intervenção social. Revista Feminismos.1(3). Set. - Dez.

Schwendler, S. F. (2009). A Participação da Mulher na Luta pela Terra: Dilemas e Conquistas. In: Fernandes, B. M.; Medeiros, L. S.; Paulilo, M. I. (org.). Lutas Camponesas Contemporâneas: condições, dilemas e conquistas. São Paulo: UNESP,. 
Valoura, L. C. Paulo Freire, o educador brasileiro autor do termo Empoderamento em seu sentido transformador. Disponível em:

https://www.researchgate.net/publication/303912423_Paulo_Freire_o_educador_brasileiro_au tor_do_termo_Empoderamento_em_seu_sentido_transformador. Acesso em: 06 de abril 2019

\section{Porcentagem de contribuição de cada autor no manuscrito}

Sandra Maria Campos Alves - 50\%

Gisélia Batista de Oliveira - 50\% 